\title{
ER-Golgi Traffic Is a Prerequisite for Efficient ER Degradation
}

\author{
Christof Taxis, ${ }^{*}$ Frank Vogel, ${ }^{+}$and Dieter H. Wolf, ${ }^{* \ddagger}$
}

\author{
*Institut für Biochemie, Universität Stuttgart, 70569 Stuttgart, Germany; and 'Max-Delbrück-Centrum \\ für Molekulare Medizin, 13125 Berlin, Germany
}

Submitted August 9, 2001; Revised February 19, 2002; Accepted February 22, 2002

Monitoring Editor: Howard Riezman

\begin{abstract}
Protein quality control is an essential function of the endoplasmic reticulum. Misfolded proteins unable to acquire their native conformation are retained in the endoplasmic reticulum, retrotranslocated back into the cytosol, and degraded via the ubiquitin-proteasome system. We show that efficient degradation of soluble malfolded proteins in yeast requires a fully competent early secretory pathway. Mutations in proteins essential for ER-Golgi protein traffic severely inhibit ER degradation of the model substrate CPY*. We found ER localization of CPY* in WT cells, but no other specific organelle for ER degradation could be identified by electron microscopy studies. Because $\mathrm{CPY}^{*}$ is degraded in COPI coat mutants, only a minor fraction of CPY* or of a proteinaceous factor required for degradation seems to enter the recycling pathway between ER and Golgi. Therefore, we propose that the disorganized structure of the ER and/or the mislocalization of Kar2p, observed in early secretory mutants, is responsible for the reduction in $\mathrm{CPY}^{*}$ degradation. Further, we observed that mutations in proteins directly involved in degradation of malfolded proteins (Der1p, Der3/Hrd1p, and Hrd3p) lead to morphological changes of the endoplasmic reticulum and the Golgi, escape of $\mathrm{CPY}^{*}$ into the secretory pathway and a slower maturation rate of wild-type CPY.
\end{abstract}

\section{INTRODUCTION}

Protein quality control with subsequent elimination of malfolded proteins or unassembled subunits is essential for cellular function. Disturbed quality control leads to disease and eventually to cell death (Plemper and Wolf, 1999; Kopito and Sitia, 2000). The endoplasmic reticulum (ER) is the folding compartment for proteins destined to function within the ER itself and for secretory proteins of the Golgi, endosomes, vacuoles, and plasma membrane as well as for proteins secreted extracellularly. It contains a multitude of folding enzymes and chaperones to perform this function (Ellgaard et al., 1999; Zapun et al., 1999). Failure in folding or in the assembly of multimeric complexes leads to recognition by the quality control machinery in the ER. The proteins are then transported back into the cytoplasm, most likely via the Sec61 translocon, and degraded by the ubiquitin-proteasome system (Kopito, 1997; Sommer and Wolf, 1997; Brodsky and McCracken, 1999; Plemper and Wolf, 1999). Polyubiquitination is mediated through the action of the E2

Article published online ahead of print. Mol. Biol. Cell 10.1091/ mbc.01-08-0399. Article and publication date are at www.molbiolcell.org/cgi/doi/10.1091/mbc.01-08-0399.

‡ Corresponding author. E-mail address: dieter.wolf@po.unistuttgart.de. enzymes, Ubc1p and Ubc7p, and the membrane bound RING-H2 ubiquitin-protein ligase (E3) Der3/Hrd1p, which is complexed to another membrane protein, Hrd3p (Hiller et al., 1996; Plemper et al., 1999; Friedländer et al., 2000; Gardner et al., 2000; Bays et al., 2001a; Deak and Wolf, 2001). The final degradation is carried out by the proteasome, a multicatalytic and multifunctional proteinase machinery (Hilt and Wolf, 2000). Depending on the nature of the malfolded substrate protein, additional components of the ubiquitination machinery (i.e., the ubiquitin conjugating enzyme [E2 Ubc6p; Biederer et al., 1996; Hiller et al., 1996) and of the lumenal ER folding machinery (the Hsp70 chaperone Kar2p, protein-disulfide isomerase [PDI], $\alpha-1,2$ mannosidase, the lectin-like protein Mnl1/Htm1 (Knop et al., 1996b; Plemper et al., 1997; Brodsky et al., 1999; Gillece et al., 1999; Jakob et al., 2001; Nakatsukasa et al., 2001) or an ER membrane protein of unknown function (Der1p; Knop et al., 1996a) are required for the degradation event.

We had previously shown that a defect in ERD1, involved in the retrieval of HDEL-containing proteins from the Golgi to the ER (Hardwick et al., 1990), leads to the escape of CPY* from the ER, despite the fact that CPY* does not contain the HDEL retrieval sequence (Knop et al., 1996a). We were, therefore, interested in the question whether the secretory competence of the ER in general is necessary for the degradation of malfolded proteins. Intracellular transport of pro- 
Table 1. Yeast strains used in this study

\begin{tabular}{|c|c|c|}
\hline Name & Genotype & Source \\
\hline W303-1B & Mat $\alpha$ ade2-1 leu2-3,112 trp1-1 ura3-1 his3-11,15 can1-100 & Chiang and Schekman (1991) \\
\hline W303-1C & W303-1B prc1-1 & Knop et al. (1996a) \\
\hline W303-CD & W303-1C $\Delta$ der1::URA3 & Knop et al. (1996a) \\
\hline W303-CF & W303-1C $\Delta$ pep $4:: H I S 3$ & Knop et al. (1996a) \\
\hline W303-CDF & W303-1C $\Delta$ der1::URA3 spep4::HIS3 & Knop et al. (1996a) \\
\hline W303-BD & W303-1B $\Delta$ der1::URA3 & Knop et al. (1996a) \\
\hline YJB009 & W303-1C $\Delta$ der3/hrd1::HIS3 & Bordallo et al. (1998) \\
\hline W303 $\Delta C$ & W303-1B $\Delta p r c 1::$ LEU2 & Plemper et al. (1999) \\
\hline YCT431 & W303-1C ufe1-1 & This work \\
\hline YCT441 & W303-1C sec $23-1$ & This work \\
\hline YCT480 & W303-1C sed5-1 & This work \\
\hline YRH68 & W303-1C Dire1::LEU2 & This work \\
\hline YCT542 & W303-1C sec23-1 Aire1::LEU2 & This work \\
\hline YCT540 & W303-1C ufe1-1 Aire1::LEU2 & This work \\
\hline YCT458 & Mat a ura3-52 prc1-1 & This work \\
\hline YCT462 & YCT458 sec12-1 & This work \\
\hline YCT460 & YCT458 sec18-1 & This work \\
\hline YCT611 & YCT458 sec $21-1$ & This work \\
\hline YCT437 & Mat a prc1-1 his4 lys2 ura3 leu2 bar1 & This work \\
\hline YCT438 & YCT437 sec27-1 & This work \\
\hline YCT614 & YCT437 sec27-1 $\Delta$ pep4::URA3 & This work \\
\hline
\end{tabular}

teins is mediated by coated vesicles: proteins are packed into COPII-coated vesicles at ER exit sites and transported to the Golgi apparatus, where they fuse with the target membrane (Rothman and Wieland, 1996; Schekman and Orci, 1996; Kuehn et al., 1998). On arrival at the Golgi complex proteins are sorted to the peripheral compartments of the cell such as vacuoles, plasma membrane, and secretory vesicles. Proteins can also be retrieved to the ER by retrograde transport from either the ER-Golgi intermediate compartment or the Golgi complex itself, by COPI-coated vesicles (Letourneur et al., 1994; Allan and Balch, 1999).

It has been previously shown that extensive protein misfolding and accumulation in the ER activates the unfolded protein response (UPR; Knop et al., 1996a; Chapman et al., 1998; Casagrande et al., 2000; Friedländer et al., 2000; Travers et al., 2000). Signaling of malfolded proteins in the ER occurs via Ire1p, a kinase/nuclease of the ER and the nuclear envelope, which activates the transcription factor Hac1p. This activation leads to transcriptional upregulation of genes necessary to relieve the cell from ER stress (Chapman et al., 1998). As one might expect, genes involved in ER degradation directly, such as DER1, DER3/HRD1, HRD3, and UBC7 are targets of Haclp (Travers et al., 2000). Furthermore, transcription of genes involved in ER-to-Golgi trafficking, protein targeting to the vacuole and the cell surface, lipid metabolism, and glycosylation are also upregulated upon ER stress (Travers et al., 2000). In this study, we investigated the requirement of a fully operational early secretory pathway and a competent UPR for efficient ER degradation. As a soluble model substrate of ER degradation in yeast we examined the disappearance of malfolded carboxypeptidase yscY (CPY*; Finger et al., 1993; Hiller et al., 1996; Knop et al., 1996a). In addition, we tested the influence of defective ER degradation on the secretory system.

\section{MATERIALS AND METHODS}

\section{Construction and Growth Conditions of Strains}

Previously described standard methods were used in media preparation and for genetic and molecular biological techniques (Guthrie and Fink, 1991; Ausubel, 1992). The Saccharomyces cerevisiae strains used in this study are summarized in Table 1 . Yeast cells were grown at $25^{\circ} \mathrm{C}$ (temperature-sensitive strains) or $30^{\circ} \mathrm{C}$. For generation of the ufe1-1 integration plasmid, pUT1 (Lewis et al., 1997), containing the ufe1-1 allele, was digested with SalI and SpeI, and the 1450 base-pair ufe1-1 fragment was ligated into pRS306 (Sikorski and Hieter, 1989) to obtain pCT27. SnaBI linearized pCT27 was used to replace the chromosomal UFE1 allele by two-step gene replacement (Scherer and Davis, 1979). RSY281 (sec23-1; Kaiser and Schekman, 1990), CBY263 (sed5-1; Cao et al., 1998), and RSY277 (sec21-1; Letourneur et al., 1994) were backcrossed multiple times through W303-1C or YCT458 to obtain the isogenic strains YCT441, YCT480, and YCT611, respectively. The IRE1 gene was deleted using plasmid pJU341, containing the IRE1 knock out fragment (Friedländer et al., 2000). Crossing of the respective single mutants to each other produced the double-mutant strains YCT541 and YCT542. To obtain strains YCT458, YCT462, YCT460, YCT437, and YCT438, BglII linearized plasmid pRS306prc1-1 (Knop et al., 1996a) was used to introduce the prc1-1 allele into strains YR1070 (wild-type), YR1068 (sec12-1), YR1069 (sec18-1; H. Rudolph), RH448 (wild-type), and RH2688 (sec27-1; Schröder-Köhne et al., 1998) using two-step gene replacement (Scherer and Davis, 1979). YCT614 was generated from strain YCT438 by deleting the PEP4 gene with PvuII-digested pWO139. Integration was confirmed by Southern blotting. Plasmid pWO139 was generated through ligation of the 1.1-kb URA3 containing an EcoRI/SmaI fragment from Yep24 (Botstein et al., 1979) into EcoRI/MscI digested plasmid pWO261. For generation of plasmid pWO261 a 1.9-kb SacI/XhoI fragment from pTZ18 (Rupp and Wolf, 1995), containing PEP4, was ligated into pBluescript $\mathrm{KS}^{+}$ (Stratagene, La Jolla, CA).

To express CPY*-HA, we fused prc1-1HA behind the TDH3 (pCT43) or CUP1 (pCT52) promoter. Similarly, PRC1 was fused behind the TDH3 promoter ( $\mathrm{pCT} 70$ ) for expression of CPY. The 
cloning strategy to obtain plasmids pCT41, pCT43, pCT52, and pCT70 is available on request. The yeast strain bearing the prc1-1HA allele was obtained according to M. Longtine (Longtine et al., 1998) using plasmid pFA6a-3HA-kanMX6. For generation of plasmid pWO152, a 3-kb BamHI/HindIII fragment, containing SEC18, was ligated into pRS426 (Christianson et al., 1992).

\section{Pulse-chase Analysis}

Yeast strains were grown logarithmically in $\mathrm{CM}$ medium and labeled for 20 min with ${ }^{35} \mathrm{~S}$-methionine (pulse). Temperature-sensitive strains were shifted to $37^{\circ} \mathrm{C}$ for the times indicated in legends to figures. After addition of an excess of nonradioactive methionine, samples were taken at the indicated time points. Cell disruption, immunoprecipitation, and SDS-PAGE were performed as previously described (Plemper et al., 1999). Curves were generated plotting the mean values of two to four independent experiments. Maturation analysis of CPY and proteinase yscA (PrA) was performed similarly, except that the strains were labeled for only $5 \mathrm{~min}$.

\section{Electron Microscopy}

For immuno-electron microscopy (EM), cells were fixed in a mixture of freshly prepared $4 \%$ formaldehyde and $0.5 \%$ glutaraldehyde in $0.1 \mathrm{M}$ citrate buffer. Temperature and $\mathrm{pH}$ were chosen according to growth conditions, as described previously (Kärgel et al., 1996; Zimmer et al., 1997). Cells were washed with PBS, and then $1 \%$ sodium metaperiodate was added for $1 \mathrm{~h}$ to prepare the cell wall for the penetration of the cryoprotectant. The hydrated specimens were immersed in a cryoprotectant mixture of $25 \%$ polyvinyl-pyrrolidone (PVP, K15/MW 10000; Fluka, Buchs, Switzerland) and 1.6 M sucrose, as described in Tokuyasu (1989). To reach complete immersion of the cryoprotectant, incubation at $30^{\circ} \mathrm{C}$ for $2-3 \mathrm{~h}$ was strictly necessary. The cells were subsequently mounted on specimen holders, frozen in liquid nitrogen, and sectioned at $-115^{\circ} \mathrm{C}$ with an ultracryotom Ultracut $S$ attached with a FCS unit (Leica, Heerbrugg, Switzerland). Ultra-thin, thawed cryosections were prepared with glass knifes and placed on formvar/carbon-coated copper grids (200 mesh, hexagonal).

Labeling with primary antibodies and immunogold-complexes (12 nm) was performed according to Griffiths (1993). Finally, the frozen-thawed sections were stained and stabilized using a mixture of freshly prepared 3\% tungstosilicic acid hydrate (STA; Fluka) and $2.5 \%$ polyvinylalcohol $\left(M_{\mathrm{r}} 10,000 ;\right.$ Sigma, Deisenhofen, Germany).

\section{CPY* Secretion}

Cells were grown to late log phase and then sedimented by centrifugation at $500 \times g$ for $5 \mathrm{~min}$. Cells were washed once with ice-cold water and centrifuged again, and the supernatants from both centrifugation steps were combined. Proteins were precipitated with trichloroacetic acid (10\%) for $30 \mathrm{~min}$ on ice and sedimented for 15 $\mathrm{min}$ at $12,000 \times \mathrm{g}$. The pellet was washed twice with ice-cold acetone and dissolved in $100 \mu \mathrm{l}$ urea buffer (5\% SDS, $8 \mathrm{M}$ urea, 200 $\mathrm{mM}$ Tris- $\mathrm{HCl}, \mathrm{pH}$ 6.8, $0.1 \mathrm{mM}$ EDTA $1.5 \%$ dithiothreithol, $0.03 \%$ bromophenol blue). To obtain the intracellular fraction of $\mathrm{CPY}^{*}$, an amount of cells corresponding to $2 \mathrm{OD}_{600}$ were alkaline lysed (Hiller et al., 1996), and the samples were subjected to SDS-PAGE and immunodetection as described previously (Knop et al., 1996a).

\section{Cycloheximide Chase}

Cells were grown to $\log$ phase at $25^{\circ} \mathrm{C}$ and incubated for $1 \mathrm{~h}$ at $37^{\circ} \mathrm{C}$. Cycloheximide was added $(0.25 \mathrm{mg} / \mathrm{ml})$, and 2 OD of cells were taken after 0 and $60 \mathrm{~min}$ of chase. Cell extracts were prepared by alkaline lysis method (Hiller et al., 1996), and the samples were subjected to SDS-PAGE followed by immunodetection (Knop et al., 1996a).

\section{Antisera}

Polyclonal anti-CPY and polyclonal anti-PrA sera were described previously (Finger et al., 1993); anti-Emp47p serum was a generous gift of H. Riezman (Schröder et al., 1995). Monoclonal anti-CPY and anti-PGK sera were purchased from Molecular Probes (Eugene, OR), HRPO-conjugated anti-mouse antibody from Sigma, monoclonal anti-HA antibody from Babco (HA.11; Berkley, CA), and antimouse immunogold-complexes (12 nm) from Dianova (Hamburg, Germany).

\section{RESULTS}

We analyzed the degradation of $\mathrm{CPY}^{*}$ in mutants defective in anterograde transport between the ER and Golgi. We used the mutant alleles sec12-1, sec23-1, ufe1-1, sed5-1, and sec18-1, which block vesicular transport at restrictive conditions (Stevens et al., 1982; Hardwick and Pelham, 1992; Lewis and Pelham, 1996). Sec12p, the nucleotide-exchange factor, which recruits Sar1p to the ER membrane (Campbell and Schekman, 1997), and Sec23p (Kuehn et al., 1998; Springer and Schekman, 1998) are both necessary for COPIIcoated vesicle formation. Ufe1p (Lewis et al., 1997; Patel et al., 1998) and Sed5p (Banfield et al., 1995; Wooding and Pelham, 1998; Tsui and Banfield, 2000) are t-SNAREs of the ER and Golgi, respectively. They are involved in the fusion of vesicles with the target membrane. Sec18p, the yeast homologue of the mammalian NSF, is required for vesicular transport in multiple stages of the secretory pathway (Graham and Emr, 1991; Mayer et al., 1996). A defect in any of these proteins leads to a considerably reduced degradation rate of $\mathrm{CPY}^{*}$ (Figure 1, $\mathrm{A}$ and $\mathrm{B}$ ). The half-life of $\mathrm{CPY}^{*}$ increases $\sim 2$ - (sec12-1, sec23-1, and sed5-1) to 6- (ufe1-1) fold in mutant cells compared with wild type. We had previously analyzed the function of Sec18p in the degradation of CPY* and $\operatorname{PrA}^{*}$, a rapidly degraded mutant form of proteinase yscA (Finger et al., 1993). Because the data had not been quantified, we had concluded that both misfolded proteins were degraded under restrictive conditions in sec18-1 cells. Reinvestigation and quantification of $\mathrm{CPY}^{*}$ degradation in these sec18-1 mutant cells, however, revealed a 6- to 7-fold increase in the half-life of CPY* (Figure 1B). The block of anterograde transport between ER and Golgi was confirmed by monitoring the maturation of proteinase yscA (PrA) in the mutant strains at restrictive conditions. In case of the ufe 1-1 strain, a tiny fraction of matured PrA was visible after 60 min of chase; all the other mutants retained PrA in the proform (Figure 1, C and D). The degradation of $\mathrm{CPY}^{*}$ observed in the sec12-1 mutant cells might be due to the action of a close homologue, Sed $4 \mathrm{p}$, which is also involved in the generation of COPII-coated vesicles at the ER membrane (Gimeno et al., 1995). We tested if a deletion of SED4 influences the degradation rate of CPY*, either as a single knockout or in conjunction with the sec12-1 mutation. In both cases there was no detectable change in the half-life of CPY* (our unpublished results).

Ufe1p is known to function in two different membrane fusion events: it is involved in the homotypic fusion of ER membranes and in the heterotypic fusion of COPI-coated vesicles with the ER membrane. To distinguish between the two different fusion events, we overexpressed the AAAATPases Cdc48p and Sec18p in temperature-sensitive $u f f$ 1-1 mutant cells. CDC48p is involved in homotypic membrane fusion, whereas Sec18p is the homologue used in heterotypic 
A

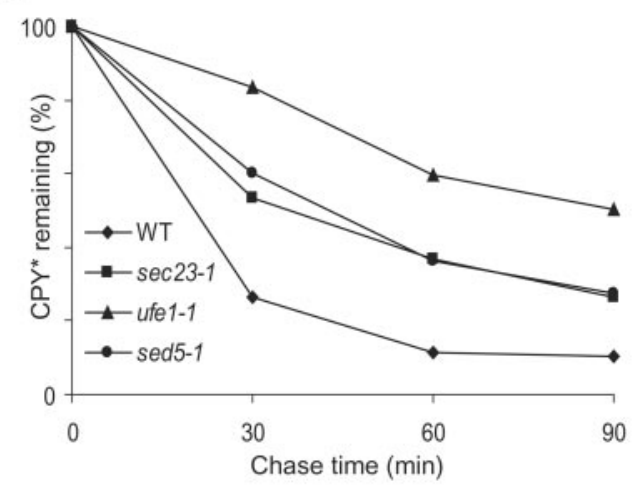

B

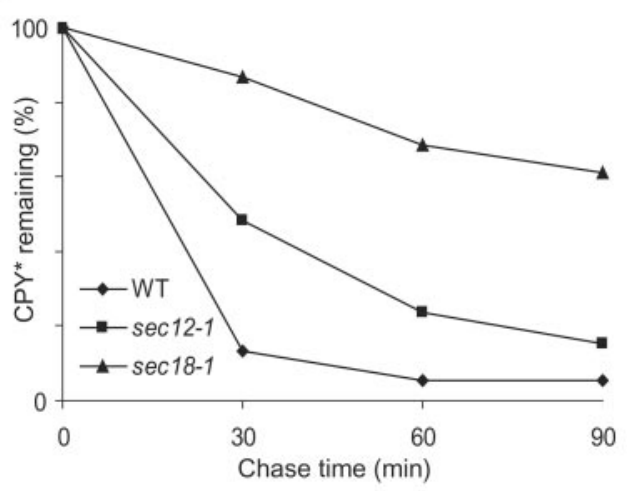

C

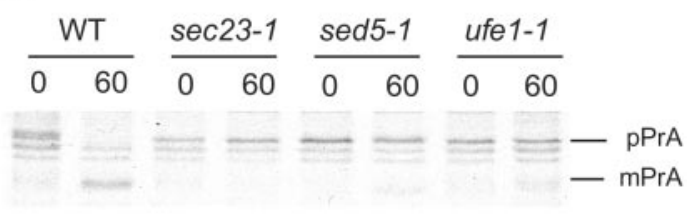

D

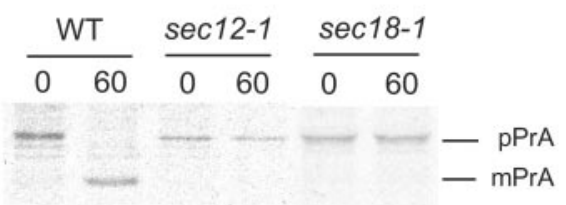

Figure 1. $\mathrm{CPY}^{*}$ degradation is impaired in mutants defective in ER-to-Golgi transport. Pulse-chase analysis was performed to measure $\mathrm{CPY}^{*}$ degradation and maturation of $\operatorname{PrA}$ in wild-type and isogenic mutant strains. Cells were shifted to restrictive temperature $5 \mathrm{~min}$ before the chase and lysed at the indicated time points. $\mathrm{CPY}^{*}$ or PrA were immunoprecipitated and separated by SDS-PAGE. Quantification was done using a PhosphorImager. (A) Formation of COPIIcoated vesicles (Sec23p) and ER and Golgi t-SNARES (Ufe1p and Sed $5 p$ ) are necessary for efficient degradation of $\mathrm{CPY}^{*}$. (B) $C P Y^{*}$ degradation requires a functional Sar1p activating factor (Sec12p) and yeast NSF (Sec18p). (C and D) Transport is blocked in the mutant strains as evidenced by the maturation defect of PrA (pPrA, p1 PrA precursor of the ER; mPrA, mature PrA of the vacuole). fusion of COPI vesicles with the ER membrane (Lewis et al., 1997; Patel et al., 1998). Overexpression of Cdc48p rescued the temperature sensitivity of the $u f e 1-1$ mutant (Patel et al., 1998) but was unable to enhance the degradation of CPY* (our unpublished results). Overexpression of Sec18p, on the other hand, did not rescue the temperature sensitivity of the ufe1-1 mutant (our unpublished results) but, interestingly, was able to partially overcome the ufe1-1-mediated degradation defect of CPY* in cells under restrictive conditions (Figure 2A).

As a control, we tested if Sec1p, a protein involved in docking of secretory transport vesicles to the plasma membrane (Novick and Schekman, 1979; Aalto et al., 1997), is involved in ER degradation. As expected, a temperaturesensitive mutant, sec1-1, did not alter the degradation of $\mathrm{CPY}^{*}$ under restrictive conditions compared with wild type (our unpublished results). This rules out any unspecific influence of defects connected to various sec mutant alleles on ER degradation (Mizuta and Warner, 1994).

Using the DNA microarray technique, Travers and coworkers could show that transcription of many genes involved in ER-Golgi transport is upregulated upon stress in the ER. Transcription of Sec23p is enhanced by induction of the UPR, whereas transcription of Ufe1p is not (Travers et al., 2000). Previous studies did not find an alteration in $\mathrm{CPY}^{*}$ degradation in $\Delta$ ire 1 cells under nonstress conditions at $30^{\circ} \mathrm{C}$ (Friedländer et al., 2000). However, we observed that the degradation rate of $\mathrm{CPY}^{*}$ is prolonged in $\Delta$ ire 1 cells at $37^{\circ} \mathrm{C}$. To examine whether there is a synergistic effect between UPR and ER-Golgi transport, we combined the $\Delta$ ire 1 mutation with mutations in Sec23p and Ufe1p. Indeed, double mutants of $\Delta$ ire 1 with either $u f e 1-1$ or sec23-1 resulted in nearly complete arrest of CPY* degradation under restrictive conditions (Figure 2, B and C).

Consequently, we tested if a block in retrograde transport from the Golgi to the ER would influence the degradation rate of CPY* as much as a block in anterograde transport does. We measured the degradation of CPY* in yeast cells defective in Sec21p or Sec27p, two components of the COPI complex (Hosobuchi et al., 1992; Duden et al., 1994; Letourneur et al., 1994). As shown in Figure 3, A and B, degradation of CPY* is only moderately affected in sec $21-1$ or sec $27-1$ cells at restrictive conditions. It is known that proteins, which cannot be retrograde transported from the Golgi to the ER, may travel to the vacuole for degradation. Therefore, we combined a mutation in Sec27p with a deletion of the PEP4 gene, leading to a proteolysis defective vacuole (Knop et al., 1993; Van Den Hazel et al., 1996), to check if vacuolar degradation contributes to the decay of CPY* in this COPI mutant. We found that degradation of $\mathrm{CPY}^{*}$ was not altered in the double mutant (Figure 3B), whereas a pep4 single mutant degrades CPY* like a wild-type strain (our unpublished results and Figure 5B). Anterograde transport is partially affected in sec21-1 and to a lesser degree in sec27-1 cells (Letourneur et al., 1994). We measured the maturation process of $\operatorname{PrA}$, applying the conditions for the CPY* degradation experiment, and found that in fact $\operatorname{PrA}$ is not fully matured in the mutant cells after 60 min of chase (Figure 3C). In wild-type cells $80 \%$ of PrA is matured after $60 \mathrm{~min}$ of chase, whereas in sec $21-1$ cells only $64 \%$ and in sec $27-1$ cells $74 \%$ is in the mature form. Retrograde transport is defective in these two mutants at $37^{\circ} \mathrm{C}$. It is known that Emp47p is 
A

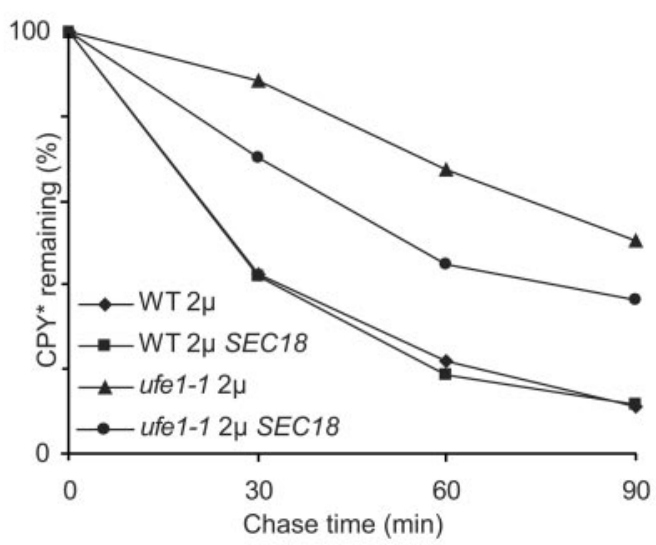

B
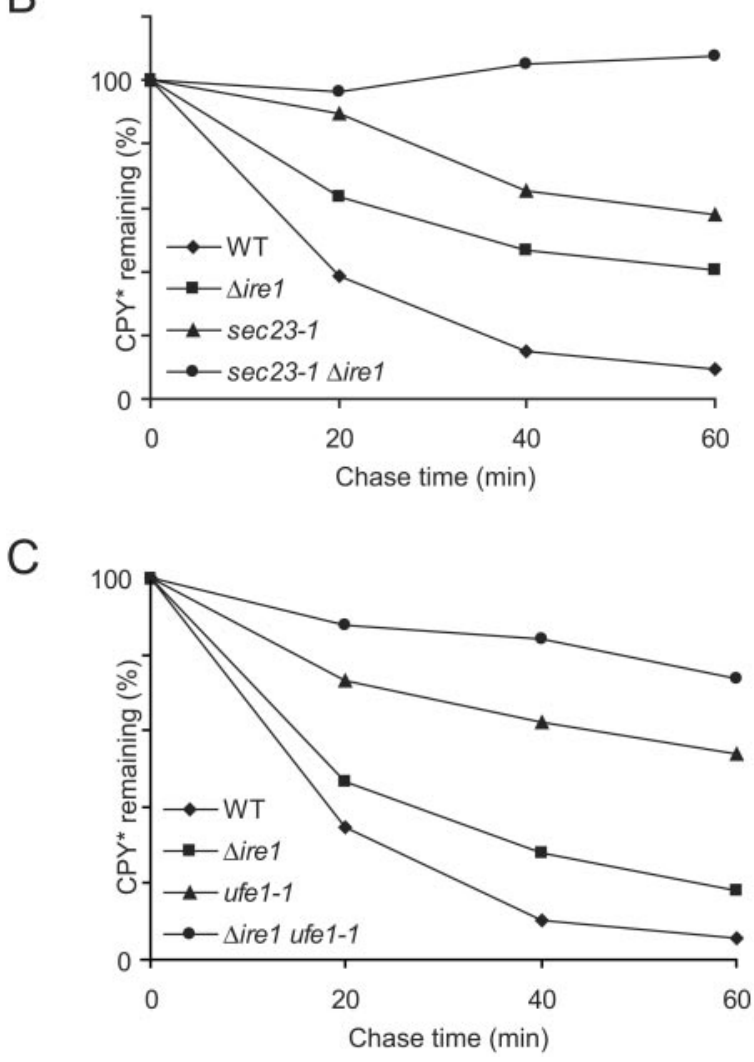

Figure 2. (A) Over expression of Sec18p partially suppresses the $\mathrm{CPY}^{*}$ degradation defect of $u f e 1-1$ mutant cells. Vector (pRS426) or SEC18 on a high copy plasmid (pWO152) were transformed into wild-type (WT) and ufe1-1 mutant cells. Pulse-chase analysis was done as described in Figure 1. (B and C) Synergistic effect of ERGolgi transport mutants and the unfolded protein response on degradation of CPY*. Pulse-chase analysis was done as described in Figure 1.

degraded in the vacuole, when its recycling via COPI-coated vesicles is inhibited (Lewis and Pelham, 1996; SchröderKöhne et al., 1998). We, therefore, tested the stability of
A

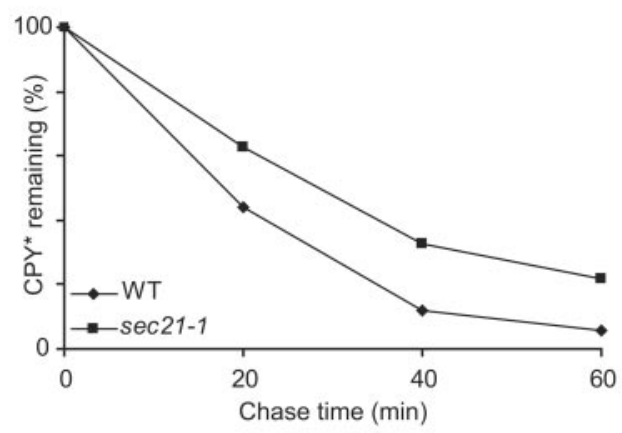

B

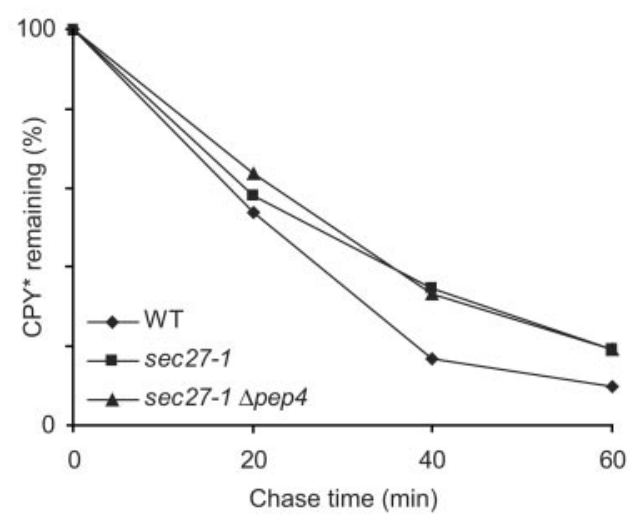

C

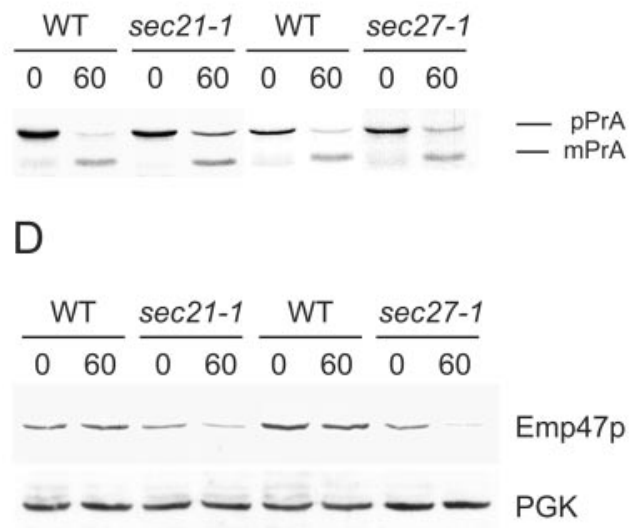

Figure 3. $\mathrm{CPY}^{*}$ degradation is affected only moderately in cells defective in COPI-coated vesicle formation at restrictive temperature. Pulse-chase analysis was performed as described in Figure 1, except that the cells were shifted to restrictive temperature $60 \mathrm{~min}$ before the chase. (A) CPY* degradation in isogenic wild-type and sec21-1 mutant strain. (B) CPY* degradation in isogenic wild-type, sec27-1, and sec27-1 $\Delta$ pep 4 mutant strains. (C) Maturation of PrA was measured in a pulsechase experiment in COPI mutant and isogenic wild-type strains. The experiment was done as described for Figure 3A, except that the cells were labeled with radioactive methionine for $10 \mathrm{~min}$. (D) COPI-coated vesicle transport is affected in the mutant strains under the conditions used. Emp47p degradation was followed in a cycloheximide chase experiment after a 60 -min preincubation at $37^{\circ} \mathrm{C}$. Equal amounts of cells were taken at the indicated time points. Pgk1p served as a loading control. 
Emp47p in sec21-1 and sec27-1 cells and found that Emp47p is degraded rapidly in the mutants, but it is stable in the respective wild-type cells at restrictive conditions (Figure 3D). This shows that even although retrograde transport is defective in these cells, CPY* is degraded efficiently.

One of the possible models that would explain these results is the existence of a special ER-derived compartment for degradation, as proposed recently for mammalian cells by Kamhi-Nesher et al. (2001). To test this model, we analyzed the localization of CPY* by electron microscopy and immuno-gold visualization of an HA-tagged version of $\mathrm{CPY}^{*}$. CPY*-HA is degraded in the same way and with similar kinetics as nontagged CPY* (our unpublished results). CPY*-HA is localized to the ER/nuclear envelope and to the peripheral ER, whereas the later compartments of the secretory pathway are almost free of label in wild-type cells (Figure 4A). A yeast strain deleted in Der1p, which is defective in the degradation of CPY* (Knop et al., 1996a), was used to analyze whether $\mathrm{CPY} Y^{*}-\mathrm{HA}$ is accumulating in a novel compartment. In $\Delta$ der 1 cells, as in wild-type, most of the CPY*-HA was found at the ER/nuclear envelope and the peripheral ER. Additionally, CPY*-HA was found in the Golgi apparatus and the vacuole, and a fraction was secreted outside the cell (Figure 4, B and C). This finding complements the results of Knop et al., 1996a, who showed Golgi glycosylation of CPY* in Der1p mutant cells. In control cells, not expressing CPY*-HA, few gold particles can typically be found inside the nucleus and in the cytosol but not in any membraneous structures (Figure 4D).

The localization of $\mathrm{CPY}^{*}$ was also analyzed by Western blotting, which confirmed the EM data: in wild-type cells a minor fraction of $\mathrm{CPY}^{*}$ was secreted into the medium, whereas in $\Delta d e r 1$ and $\Delta d e r 3 / h r d 1$ cells more $\mathrm{CPY}^{*}$ appeared in the medium (Figure 5A). Additionally, the amount of secreted CPY* was higher than that of Kar2p in these cells, as evidenced by a very faint Kar2p signal in the extracellular fraction (Figure 5A). It is known that Kar2p is secreted when the HDEL retrieval pathway is saturated (Belden and Barlowe, 2001). To analyze the fate of CPY* in the vacuole, we performed pulse-chase analysis in cells with impaired vacuolar degradation due to deletion of the PEP4 gene (Knop et al., 1993; Van Den Hazel et al., 1996). In $\Delta$ pep4 cells CPY* was degraded as in wild-type cells; however, in $\Delta$ der1 $\Delta$ pep 4 double mutants the degradation was slower than in $\Delta$ der 1 single mutants (Figure 5B).

The EM images revealed that in cells deficient in ER degradation some interesting morphological changes are visible. In these cells $(\Delta$ der $1, \Delta$ der $3 / h r d 1$, and $\Delta h r d 3)$ the Golgi apparatus appears as stacked cisternae in many cells (Figure 6, B and C, and our unpublished results), whereas a typical wild-type cell contains disconnected Golgi structures (Figure 6A). Stacked Golgi structures were previously observed in yeast mutant cells defective in intra-Golgi transport, such as in sec7-1 cells at nonpermissive conditions (Rambourg et al., 1993) but rarely in wild-type cells (Rambourg et al., 1995). Mutants defective in ER degradation $(\Delta$ der $1, \Delta$ der $3 / h r d 1$, and $\Delta h r d 3$ ) also exhibit a considerably proliferated ER (Figure 6D and our unpublished results). These morphological changes are absent in cells where ER degradation is abolished in conjunction with the unfolded protein response. In $\Delta$ der 1 $\Delta$ ire 1 cells the ER does not proliferate and the Golgi apparatus has normal appearance (our unpublished results).
These observations raised the question of whether the morphological changes in the ER and Golgi influence the secretory function of these organelles. To address this question, we measured the maturation kinetics of wild-type CPY in wild-type and $\Delta$ der 1 mutant cells. Distinct forms of CPY reflect the transport of this enzyme from the ER via the Golgi to the vacuole. The core glycosylated pro-CPY precursor in the ER has a molecular mass of $\sim 67 \mathrm{kDa}$ (p1CPY). In the Golgi, the carbohydrate of CPY is modified, resulting in the p2CPY form of $69 \mathrm{kDa}$. After transport to the vacuole, CPY is matured (mCPY) to a final form of $61 \mathrm{kDa}$ (Rendueles and Wolf, 1988). Figure 7, A and B, shows that the transport of wild-type CPY is not delayed to a significant degree in cells lacking Der1p. The calculated ratio between Golgi p2CPY and vacuolar $\mathrm{mCPY}$ species is almost the same in wild-type and $\Delta$ der 1 mutant cells at the different time points (Figure 7B). However, when CPY*-HA is expressed simultaneously with wild-type CPY in Der1p-deficient cells, the maturation of CPY from the p2CPY Golgi form to the mature vacuolar form is considerably delayed (Figure 7C). The ratio between p2 and mCPY is higher in $\Delta$ der 1 than in wild-type cells when CPY*-HA is coexpressed, indicating a slower transport of the p2CPY form (Figure 7D). Surprisingly, the exit of proCPY from the ER seems to be undisturbed: there is no difference in the rate of disappearance of p1CPY between wild-type and $\Delta$ der 1 cells expressing CPY*-HA (Figure $7 \mathrm{~F}$ ), and it is also the same as that observed in wild-type cells not coexpressing CPY or CPY*-HA (our unpublished results). As a control, we expressed CPY exogenously in wild-type and $\Delta$ der 1 cells and followed the maturation of CPY. Under these conditions, every step of the process was delayed in both strains, starting with a slower exit from the ER (Figure 7, E and F). Taken together, the EM data and the CPY maturation experiments suggest that escape of unfolded proteins from the ER disturbs the secretory competence of the later stages of the secretory pathway.

\section{DISCUSSION}

Using mutants defective in ER-to-Golgi traffic, we discovered a connection between the secretory competence of the ER itself and the degradation of the ERAD substrate CPY*. Mutants defective in Ufe1p, Sec12p, Sec23p, Sed5p, and Sec18p exhibited an extended half-life of CPY* (Figure 1). After completion of our studies, reports appeared that also communicate disturbed degradation of soluble ER degradation substrates in mutants defective in ER-Golgi transport (Caldwell et al., 2001; Vashist et al., 2001). The authors give two explanations for the involvement of ER-to-Golgi transport in ER degradation: (i) Soluble ER substrates may travel to the Golgi and back to the ER, either to receive a modification that enhances degradation (Caldwell et al., 2001) or as the default route to degradation (Vashist et al., 2001). (ii) Alternatively, an yet unidentified factor, which is required for the degradation of soluble substrates, cycles between ER and Golgi. In this model, the substrate itself remains in the ER (Caldwell et al., 2001).

Our results lead to different conclusions: in the sec12-1, sec18-1, and sec23-1 mutants, ER-to-Golgi transport is blocked completely as evidenced by the lack of the Golgi localized p2CPY species (Stevens et al., 1982) or by the maturation defect of PrA (Figure 1, C and D). In contrast, 

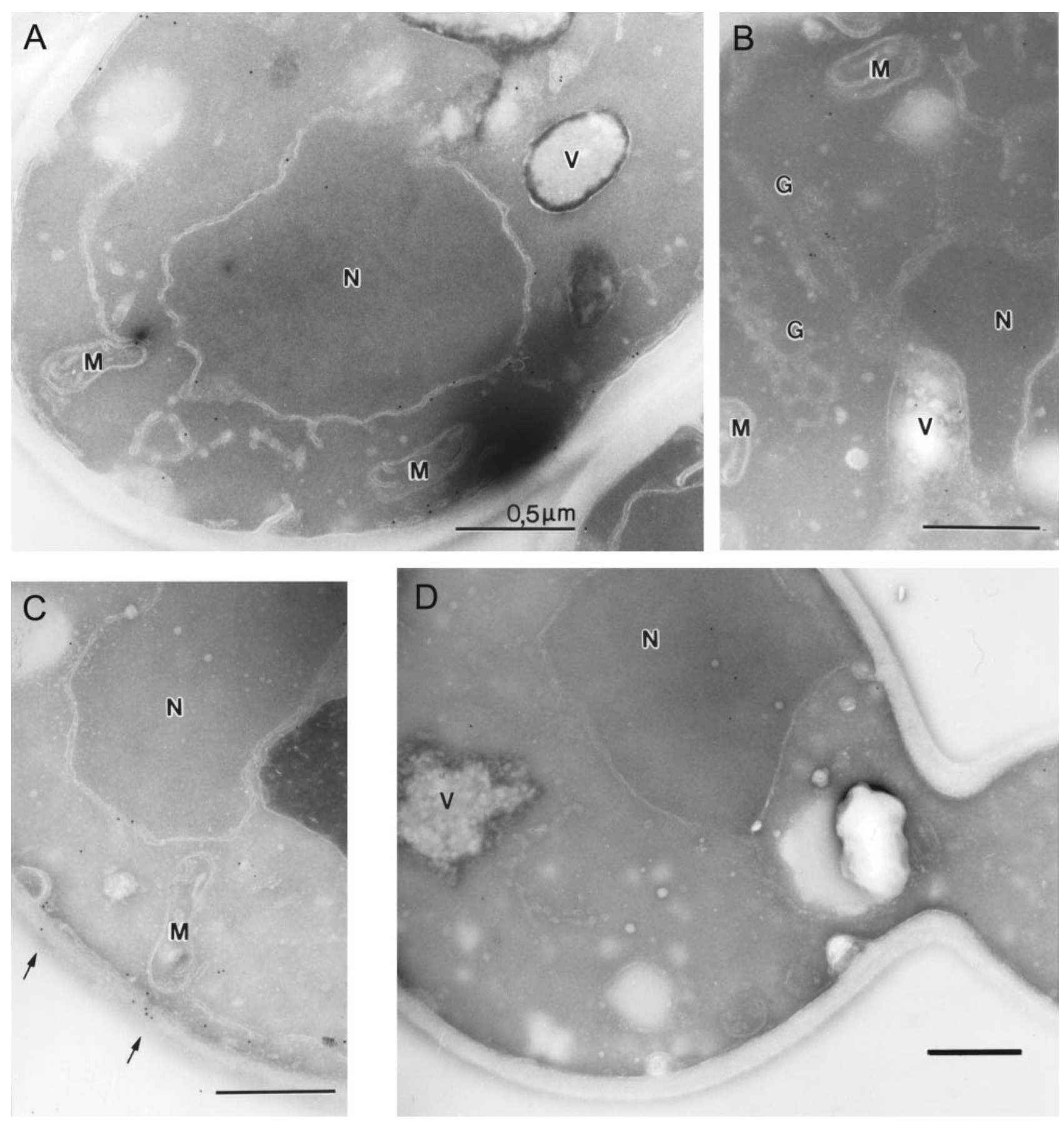

Figure 4. Localization of CPY*-HA by immuno-EM. Ultra-thin cryosections of wild-type (A) and Der1p-deleted cells (B and C) expressing HA-tagged CPY* or wild-type cells without tag (D) were labeled with antibodies against HA and anti-mouse-gold complexes (12 nm). Yeast strains in A, B, and C were transformed with plasmid pCT52, carrying CPY*-HA under the control of the CUP1 promoter. The expression of $\mathrm{CPY}^{*}$-HA was induced with addition of copper sulfate $(100 \mu \mathrm{M}$ final concentration) for $3 \mathrm{~h}$. (A) CPY*-HA is localized to the ER in wild-type cells. (B) $\mathrm{CPY}^{*}$-HA is distributed in structures of the secretory system in $\Delta$ der 1 cells. (C) $\Delta$ der 1 cells secrete CPY*-HA to the outside of the cell. (D) Unspecific staining of the used antibodies in wild-type cells. N, nucleus; M, mitochondrion; V, vacuole; G, Golgi elements. Bars, 500 nm.

degradation of $\mathrm{CPY}^{*}$ is not completely blocked in these mutants (Figure 1, A and B). Instead, degradation of CPY* takes place at different rates in the various ER-Golgi traffick- ing mutants tested; the delay in degradation ranges between a factor of 2 (sec12-1, sec23-1, and sed5-1 mutant strains) and 6-7 (sec18-1 and ufe1-1 mutants). Deletion of Sed4p, a close 
A

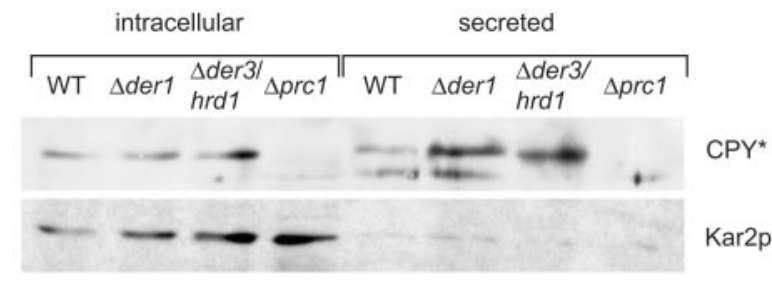

B

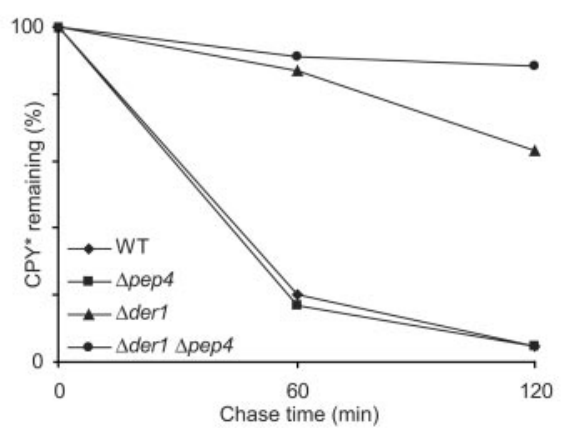

Figure 5. (A) $\mathrm{CPY}^{*}$ is secreted into the medium. Cellular and secreted CPY* was analyzed by SDS-PAGE and immunodetection. The same blot was reprobed against Kar2p. Approximately five times more material was loaded in the extracellular fraction. (B) Vacuolar hydrolysis contributes to degradation of $\mathrm{CPY}^{*}$ in $\Delta$ der 1 cells. Degradation of $\mathrm{CPY}^{*}$ was measured by pulse-chase analysis in yeast strains defective in vacuolar hydrolysis $(\Delta p e p 4)$, ER degradation $(\Delta$ der 1$)$, or double mutants $(\Delta$ pep $4 \Delta$ der 1$)$.

homologue of Sec12p, in the presence of the sec12-1 mutation, did not enhance the half-life of CPY*. Because ER-toGolgi traffic is blocked in these mutants, it is hard to envisage how some CPY* could still reach the Golgi to receive a specific modification or why the degradation route would be changed in sec12-1, sec23-1, or sed5-1 but not in sec18-1 or ufe 1-1 cells. In COPI mutant cells (sec21-1 and sec27-1), only a moderate alteration in the degradation of $\mathrm{CPY}^{*}$ compared with wild-type is visible (Figure $3, A$ and B), despite the fact that retrograde traffic from the Golgi to the ER is defective (Figure 3D and Letourneur et al., 1994). If CPY* would travel to the Golgi and back to the ER before degradation, one would expect a much larger influence of COPI-coat mutants on degradation of CPY*. Because the half-life of CPY* is not increased in sec27-1 spep4 double-mutant cells, we conclude that the vacuole does not contribute to the degradation seen in sec 27-1 cells (Figure 3B). All together, the transport defects of the various mutants cannot be correlated with the degradation pattern of CPY*. These findings, therefore, argue against the idea of a relocation of $\mathrm{CPY}^{*}$ to the Golgi and then back to the ER or of the recycling of a proteinaceous factor between these compartments for efficient degradation of CPY*. Only a yet-unknown Golgi-ER retrieval mechanism could possibly apply for a cycling-dependent degradation mechanism. Another recent publication reports that mutations in the early secretory pathway severely affect the structure of the ER (Prinz et al., 2000). They show that ufe1-1 or sec23-1 mutant cells, two mutants also used in our studies, exhibit a dramatically reduced amount of peripheral ER and a considerably disorganized organelle at nonpermissive temperature (Prinz et al., 2000). We find that under the same conditions degradation of $\mathrm{CPY}^{*}$ is prolonged in these mutants (Figure 1A). Another possible explanation is that the mislocalization of Kar2p observed in various ER-Golgi transport mutants (Nishikawa et al., 1994) leads to defective degradation. Kar2p is necessary for degradation of $\mathrm{CPY}^{*}$ (Plemper et al., 1997) but is not involved in the degradation of membrane proteins (Plemper et al., 1998; Kiser et al., 2001; Zhang et al., 2001). This model would explain why misfolded membrane proteins are degraded efficiently in the ER-Golgi transport mutants (Biederer et al., 1996; Katzmann et al., 1999; Vashist et al., 2001), whereas CPY* is not. Taken together, we conclude that the morphological disturbance of the ER, mislocalization of Kar2p, or both, are the cause of the changes in $\mathrm{CPY}^{*}$ degradation. Analysis of the localization of HA-tagged $\mathrm{CPY}^{*}$ via immuno-gold EM revealed that the protein resides at the ER/nuclear envelope and the peripheral ER. These EM images do not indicate the existence of a novel compartment, specialized in ER degradation (Figure 4, A-C), as recently proposed for mammalian cells (KamhiNesher et al., 2001). In the light of the EM data, the degradation behavior of CPY* in the ER-Golgi transport mutants as well as the data of Prinz et al. (2000) and Nishikawa et al. (1994), we suggest that the decrease in degradation of CPY* is due to indirect or secondary effects caused by the mutations that lead to impaired ER-Golgi transport. The severe alteration in $\mathrm{CPY}^{*}$ degradation observed in double mutants defective in Sec23p or Ufe1p and UPR signaling due to deletion of Ire1p (Figure 2, B and C), can be explained similarly: the amount of ER is diminished, chaperones like Kar2p are mislocalized, and the possibility to increase expression of proteins involved in ER-stress relieve is abolished. Recovery of $\mathrm{CPY}^{*}$ degradation upon overexpression of Sec18p in $u f e 1-1$ mutants indicates that the involvement of Ufe1p in vesicular transport is necessary to maintain proper $\mathrm{CPY}^{*}$ degradation and that this is independent of its involvement in homotypic membrane fusion exerted together with Cdc48p (Figure 2A). Recent studies show that Cdc48p does indeed take part in $\mathrm{CPY}^{*}$ degradation, being involved in retro-translocation of the malfolded protein into the cytosol (Ye et al., 2001; Bays et al., 2001b; Rabinovitch et al., 2002; Jarosch et al., 2002).

The ER is considerably enlarged in $\Delta$ der $1, \Delta \operatorname{der} 3 / \mathrm{hrd} 1$, and $\Delta h r d 3$ cells (Figure 6D and our unpublished results). This alteration is most likely controlled by the UPR, because many genes involved in lipid metabolism are also upregulated upon ER stress (Travers et al., 2000). As expected, a $\Delta$ der1 $\Delta$ ire1 double knockout strain has no proliferated ER (our unpublished results). The appearance of Golgi stacks could indicate a defect in intra-Golgi transport in the mutants deficient in ER degradation, which is less severe than the one seen in the sec7-1 mutant at restrictive conditions but significant enough to change the morphology of the organelle. On disruption of CPY* degradation by deletion of Der1p, we find some CPY*-HA in the Golgi apparatus, in the vacuole and in secreted form (Figure 4, B and C). This indicates a "leakage" of CPY*-HA out of the ER under these conditions. In addition, in a strain deleted for Der1p and Pep4p, CPY* has a longer half-life than in a strain lacking only Der1p, indicating transport of a fraction of $\mathrm{CPY}^{*}$ into the vacuole. This finding complements the observation of Knop et al. (1996a), who reported some Golgi glycosylation 

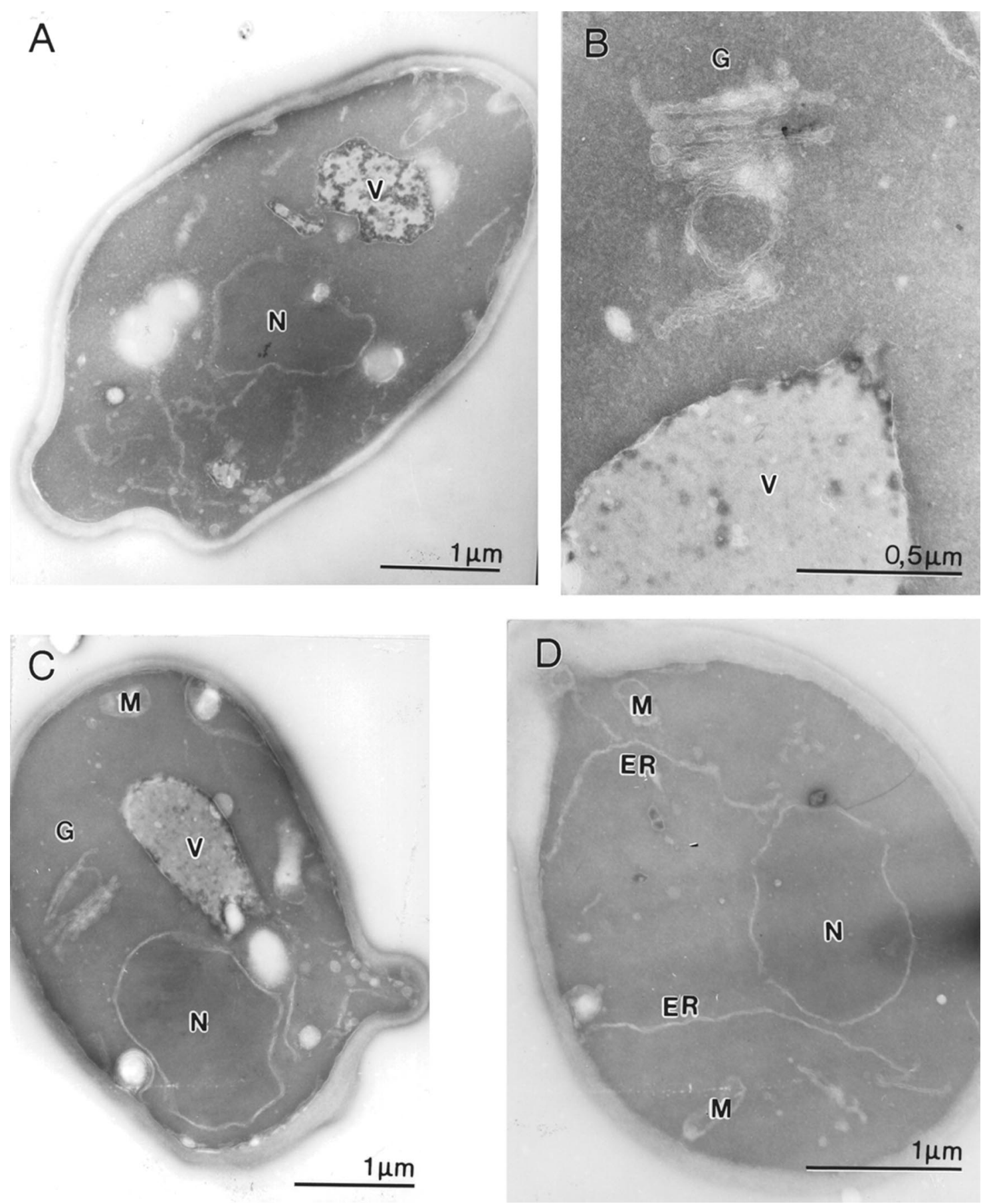

Figure 6. Morphology of secretory organelles is changed in mutants defective in ER degradation. (A) Wild-type. (B) Golgi structure in $\Delta$ der1 cells. (C) Golgi structures present in Der3/Hrd1p-deficient cells. (D) ER proliferates in $\Delta d e r 3 / h r d 1$ cells. N, nucleus; M, mitochondrion; V, vacuole; ER, endoplasmic reticulum. Bars, 1000 and $500 \mathrm{~nm}$, respectively.

of $\mathrm{CPY}^{*}$ in $\Delta$ der1 cells. Soluble, misfolded proteins can escape from the ER when their degradation is abolished. The reason is probably the saturation of the retrieval pathway from the Golgi back to the ER when too many unfolded proteins are present in the ER. It is known that the HDEL receptor takes part in the retention of unfolded proteins in the ER by recycling them back from the Golgi (Knop et al., 1996a; Yamamoto et al., 2001). Unfolded proteins that escape the retention machinery travel along the secretory pathway to the vacuole or are secreted (Figures 4, B and C, and 5). 
A

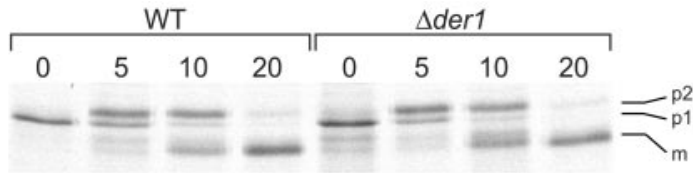

B

\begin{tabular}{c|c|c}
$\begin{array}{c}\text { Chase time } \\
\text { (min) }\end{array}$ & \multicolumn{2}{|c}{ Ratio $\mathrm{p} 2 / \mathrm{mCPY}$} \\
WT & \multicolumn{1}{c}{$\Delta$ der1 } \\
\hline 0 & 1,0 & 0,8 \\
5 & 4,2 & 6,0 \\
10 & 1,2 & 1,4 \\
20 & 0,2 & 0,2
\end{tabular}

C

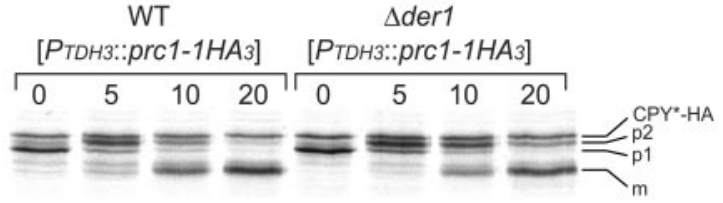

D

\begin{tabular}{|c|c|c|}
\hline \multirow{3}{*}{$\begin{array}{l}\text { Chase time } \\
\text { (min) }\end{array}$} & \multicolumn{2}{|c|}{ Ratio $\mathrm{p} 2 / \mathrm{mCPY}$} \\
\hline & WT & $\Delta d e r 1$ \\
\hline & $\mathrm{CPY}^{*} \mathrm{HA}$ & $\mathrm{CPY}{ }^{*} \mathrm{HA}$ \\
\hline 0 & 5,3 & 5,3 \\
\hline 5 & 3,7 & 10,0 \\
\hline 10 & 0,8 & 1,9 \\
\hline 20 & 0,2 & 0,4 \\
\hline
\end{tabular}

E

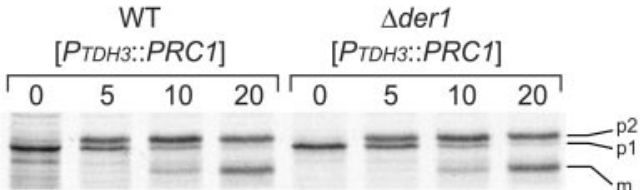

$\mathrm{F}$

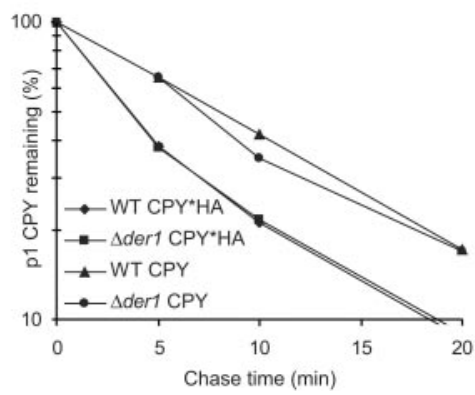

Figure 7. Maturation of CPY is prolonged, upon presence of unfolded proteins in the secretory pathway. Cells expressing CPY were labeled for $5 \mathrm{~min}$ with radioactive methionine. Cells were lysed at the indicated time points and treated as described in Figure 1. The positions of $\mathrm{p} 1$ (ER), p2 (Golgi), $\mathrm{m}$ (vacuolar) CPY and $\mathrm{CPY}^{*}$-HA are shown. (A) Maturation of CPY is not dependent on the presence of Der1p. (B) Calculated ratio between $\mathrm{p} 2$ and $\mathrm{mCPY}$ in wild-type and $\Delta$ der 1 cells. (C) Expression of CPY*-HA leads to delay in maturation of CPY in $\Delta$ der1 cells. Plasmid pCT43, carrying $\mathrm{CPY}^{*}$-HA under the control of the TDH3 promoter, was introduced into wild-type and $\Delta$ der 1 cells. (D) Calculated ratio between $\mathrm{p} 2$ and $\mathrm{mCPY}$ in wild-type and $\Delta$ der 1 cells expressing additional CPY ${ }^{*}-\mathrm{HA}$. (E) Expression of additional CPY from the TDH3 promoter leads to delayed maturation of CPY in wild-type and $\Delta \operatorname{der} 1$ cells. (F) Conversion of the $\mathrm{p} 1$-form to the $\mathrm{p} 2 \mathrm{Golgi}$ form of $\mathrm{CPY}$ in wild-type and $\Delta$ der1 cells expressing additional CPY or CPY*-HA, respectively.
This seems to disturb the secretory pathway in a yet unknown way, as delivery of wild-type CPY from the Golgi to the vacuole is delayed in $\Delta$ der 1 cells simultaneously expressing malfolded CPY*-HA (Figure 7). This delay can be explained by a defect in transport through the Golgi due to the presence of misfolded proteins or, alternatively, by a competition between CPY and CPY*-HA for the CPY sorting receptor, Vps10p (Stack et al., 1995). Perturbations in vacuolar function may also explain this phenomenon. The maturation defect observed in $\Delta$ der1 cells coexpressing CPY*-HA is not simply a consequence of overloading in the secretory pathway. Overloading through expression of additional CPY results in slower transport in every step of the secretory pathway, e.g., the half-life in exit from the ER is roughly doubled (Figure 7F). In $\Delta$ der1 cells expressing CPY*-HA only the later transport or maturation steps are affected, which seems to be a consequence of unfolded proteins present in the secretory pathway (Figure 7, C and D). The data presented here indicate that efficient ER degradation requires an ER fully competent in secretion and, vice versa, that efficient secretion depends on an undisturbed quality control machinery in the ER.

\section{ACKNOWLEDGMENTS}

The authors thank M. Vogel for the preparation of the cryosections, R. Hitt, J. Strayle, H. Rudolph, H. Pelham, T. Sommer, H. Riezman, and C. Barlowe for antibodies, plasmids, and strains. We are grateful to Z. Kostova, R. Hitt, J. Strayle, S. Jäger, and the members of the Sommer lab for helpful discussions and Elisabeth Tosta for help with the manuscript. This work was supported by the Deutsche Forschungsgemeinschaft, Bonn; the German-Israeli Project Cooperation (DIP) of the Bundesministerium für Bildung und Forschung (BMBF); and the Fonds der Chemischen Industrie, Frankfurt.

\section{REFERENCES}

Aalto, M.K., Jantti, J., Ostling, J., Keranen, S., and Ronne, H. (1997). Mso1p: a yeast protein that functions in secretion and interacts physically and genetically with Sec1p. Proc. Natl. Acad. Sci. USA 94, 7331-7336.

Allan, B.B., and Balch, W.E. (1999). Protein sorting by directed maturation of Golgi compartments. Science 285, 63-66.

Ausubel, F.M., Kingston, R.E., Seidman, F.G., Struhl, K., Moore, D.D., Brent, R., and Smith, F.A. (1992). Current protocols in molecular biology. New York: Greene.

Banfield, D.K., Lewis, M.J., and Pelham, H.R. (1995). A SNARE-like protein required for traffic through the Golgi complex. Nature 375, 806-809.

Bays, N.W., Gardner, R.G., Seelig, L.P., Joazeiro, C.A., and Hampton, R.Y. (2001a). Hrd1p/Der3p is a membrane-anchored ubiquitin ligase required for ER- associated degradation. Nat. Cell Biol. 3, $24-29$.

Bays, N.W., Wilhovsky, S.K., Goradia, A., Hodgkiss-Harlow, K., and Hampton, R.Y. (2001b). HRD4/NPL4 is required for the proteasomal processing of ubiquitinated ER proteins. Mol. Biol. Cell 12, 4114-4128.

Belden, W.J., and Barlowe, C. (2001). Deletion of yeast p24 genes activates the unfolded protein response. Mol. Biol. Cell 12, 957-969.

Biederer, T., Volkwein, C., and Sommer, T. (1996). Degradation of subunits of the Sec61p complex, an integral component of the ER 
membrane, by the ubiquitin-proteasome pathway. EMBO J. 15, 2069-2076.

Botstein, D., Falco, S.C., Stewart, S.E., Brennan, M., Scherer, S., Stinchcomb, D.T., Struhl, K., and Davis, R.W. (1979). Sterile host yeasts (SHY): a eukaryotic system of biological containment for recombinant DNA experiments. Gene 8, 17-24.

Brodsky, J.L., and McCracken, A.A. (1999). ER protein quality control and proteasome-mediated protein degradation. Semin. Cell Dev. Biol. 10, 507-513.

Brodsky, J.L., Werner, E.D., Dubas, M.E., Goeckeler, J.L., Kruse, K.B., and McCracken, A.A. (1999). The requirement for molecular chaperones during endoplasmic reticulum-associated protein degradation demonstrates that protein export and import are mechanistically distinct. J. Biol. Chem. 274, 3453-3460.

Caldwell, S.R., Hill, K.J., and Cooper, A.A. (2001). Degradation of endoplasmic reticulum (ER) quality control substrates requires transport between the ER and Golgi. J. Biol. Chem. 276, 23296-23303.

Campbell, J.L., and Schekman, R. (1997). Selective packaging of cargo molecules into endoplasmic reticulum-derived COPII vesicles. Proc. Natl. Acad. Sci. USA 94, 837-842.

Cao, X., Ballew, N., and Barlowe, C. (1998). Initial docking of ERderived vesicles requires Usolp and Ypt1p but is independent of SNARE proteins. EMBO J. 17, 2156-2165.

Casagrande, R., Stern, P., Diehn, M., Shamu, C., Osario, M., Zuniga, M., Brown, P.O., and Ploegh, H. (2000). Degradation of proteins from the ER of $S$. cerevisiae requires an intact unfolded protein response pathway. Mol. Cell 5, 729-735.

Chapman, R., Sidrauski, C., and Walter, P. (1998). Intracellular signaling from the endoplasmic reticulum to the nucleus. Annu. Rev. Cell Dev. Biol. 14, 459-485.

Christianson, T.W., Sikorski, R.S., Dante, M., Shero, J.H., and Hieter, P. (1992). Multifunctional yeast high-copy-number shuttle vectors. Gene 110, 119-122.

Deak, P.M., and Wolf, D.H. (2001). Membrane topology and function of Der3/Hrd1p as a ubiquitin-protein ligase (E3) involved in endoplasmic reticulum degradation. J. Biol. Chem. 276 10663-10669.

Duden, R., Hosobuchi, M., Hamamoto, S., Winey, M., Byers, B., and Schekman, R. (1994). Yeast beta- and beta'-coat proteins (COP). Two coatomer subunits essential for endoplasmic reticulum-to-Golgi protein traffic. J. Biol. Chem. 269, 24486-24495.

Ellgaard, L., Molinari, M., and Helenius, A. (1999). Setting the standards: quality control in the secretory pathway. Science 286, 1882-1888

Finger, A., Knop, M., and Wolf, D.H. (1993). Analysis of two mutated vacuolar proteins reveals a degradation pathway in the endoplasmic reticulum or a related compartment of yeast. Eur. J. Biochem. 218, 565-574.

Friedländer, R., Jarosch, E., Urban, J., Volkwein, C., and Sommer, T. (2000). A regulatory link between ER-associated protein degradation and the unfolded-protein response. Nat. Cell Biol. 2, 379-384.

Gardner, R.G., Swarbrick, G.M., Bays, N.W., Cronin, S.R., Wilhovsky, S., Seelig, L., Kim, C., and Hampton, R.Y. (2000). Endoplasmic reticulum degradation requires lumen to cytosol signaling. Transmembrane control of Hrd1p by Hrd3p. J. Cell Biol. 151, 69-82.

Gillece, P., Luz, J. M., Lennarz, W. J., de La Cruz, F. J., and Römisch, K. (1999). Export of a cysteine-free misfolded secretory protein from the endoplasmic reticulum for degradation requires interaction with protein disulfide isomerase. J. Cell Biol. 147, 1443-1456.

Gimeno, R.E., Espenshade, P., and Kaiser, C.A. (1995). SED4 encodes a yeast endoplasmic reticulum protein that binds Sec16p and participates in vesicle formation. J. Cell Biol. 131, 325-338.
Graham, T.R., and Emr, S.D. (1991). Compartmental organization of Golgi-specific protein modification and vacuolar protein sorting events defined in a yeast sec18 (NSF) mutant. J. Cell Biol. 114, 207-218.

Griffiths, G. (1993). Labeling reactions for immunocytochemistry. In: Fine structure immunocytochemistry, ed. G. Griffiths, Berlin, Germany: Springer, 237-275.

Guthrie, C., and Fink., G. R. (1991). Guide to yeast genetics and molecular biology, vol. 194. New York: Academic Press.

Hardwick, K.G., Lewis, M.J., Semenza, J., Dean, N., and Pelham, H.R. (1990). ERD1, a yeast gene required for the retention of luminal endoplasmic reticulum proteins, affects glycoprotein processing in the Golgi apparatus. EMBO J. 9, 623-630.

Hardwick, K.G., and Pelham, H.R. (1992). SED5 encodes a 39-kD integral membrane protein required for vesicular transport between the ER and the Golgi complex. J. Cell Biol. 119, 513-521.

Hiller, M.M., Finger, A., Schweiger, M., and Wolf, D.H. (1996). ER degradation of a misfolded luminal protein by the cytosolic ubiquitin-proteasome pathway. Science 273, 1725-1728.

Hilt, W., and Wolf, D.H. (2000). Proteasomes. The world of regulatory proteolysis, ed. W. Hilt, D. H. Wolf, Austin: Landes Bioscience (Georgetown/Eurekah.com), 1-387.

Hosobuchi, M., Kreis, T., and Schekman, R. (1992). SEC21 is a gene required for ER-to-Golgi protein transport that encodes a subunit of a yeast coatomer. Nature 360, 603-605.

Jakob, C.A., Bodmer, D., Spirig, U., Battig, P., Marcil, A., Dignard, D., Bergeron, J.J., Thomas, D.Y., and Aebi, M. (2001). Htm1p, a mannosidase-like protein, is involved in glycoprotein degradation in yeast. EMBO Rep. 2, 423-430.

Jarosch, E., Taxis, C., Volkwein, C., Bordallo, J., Finley, D., Wolf, D. H., and Sommer, T. (2002). Protein dislocation from the ER requires polyubiquitination, and the AAA-ATPase Cdc48. Nat. Cell Biol. 4, 134-139.

Kaiser, C.A., and Schekman, R. (1990). Distinct sets of SEC genes govern transport vesicle formation and fusion early in the secretory pathway. Cell 61, 723-733.

Kamhi-Nesher, S., Shenkman, M., Tolchinsky, S., Fromm, S.V., Ehrlich, R., and Lederkremer, G.Z. (2001). A novel quality control compartment derived from the endoplasmic reticulum. Mol. Biol. Cell 12, 1711-1723.

Kärgel, E., Menzel, R., Honeck, H., Vogel, F., Bohmer, A., and Schunck, W.H. (1996). Candida maltosa NADPH-cytochrome P450 reductase: cloning of a full-length cDNA, heterologous expression in Saccharomyces cerevisiae and function of the N-terminal region for membrane anchoring and proliferation of the endoplasmic reticulum. Yeast 12, 333-348.

Katzmann, D.J., Epping, E.A., and Moye-Rowley, W.S. (1999). Mutational disruption of plasma membrane trafficking of Saccharomyces cerevisiae Yor1p, a homologue of mammalian multidrug resistance protein. Mol. Cell Biol. 19, 2998-3009.

Kiser, G.L., Gentzsch, M., Kloser, A.K., Balzi, E., Wolf, D.H., Goffeau, A., and Riordan, J.R. (2001). Expression and degradation of the cystic fibrosis transmembrane conductance regulator in Saccharomyces cerevisiae. Arch. Biochem. Biophys. 390, 195-205.

Knop, M., Finger, A., Braun, T., Hellmuth, K., and Wolf, D.H. (1996a). Der1, a novel protein specifically required for endoplasmic reticulum degradation in yeast. EMBO J. 15, 753-763.

Knop, M., Hauser, N., and Wolf, D.H. (1996b). N-Glycosylation affects endoplasmic reticulum degradation of a mutated derivative of carboxypeptidase yscY in yeast. Yeast 12, 1229-1238. 
Knop, M., Schiffer, H.H., Rupp, S., and Wolf, D.H. (1993). Vacuolar/ lysosomal proteolysis: proteases, substrates, mechanisms. Curr. Opin. Cell Biol. 5, 990-996.

Kopito, R.R. (1997). ER quality control: the cytoplasmic connection. Cell 88, 427-430.

Kopito, R.R., and Sitia, R. (2000). Aggresomes, and Russell bodies Symptoms of cellular indigestion? EMBO Rep. 1, 225-231.

Kuehn, M.J., Herrmann, J.M., and Schekman, R. (1998). COPII-cargo interactions direct protein sorting into ER-derived transport vesicles. Nature 391, 187-190.

Letourneur, F., Gaynor, E.C., Hennecke, S., Demolliere, C., Duden, R., Emr, S.D., Riezman, H., and Cosson, P. (1994). Coatomer is essential for retrieval of dilysine-tagged proteins to the endoplasmic reticulum. Cell 79, 1199-1207.

Lewis, M.J., and Pelham, H.R. (1996). SNARE-mediated retrograde traffic from the Golgi complex to the endoplasmic reticulum. Cell 85, 205-215.

Lewis, M.J., Rayner, J.C., and Pelham, H.R. (1997). A novel SNARE complex implicated in vesicle fusion with the endoplasmic reticulum. EMBO J. 16, 3017-3024.

Longtine, M.S., McKenzie, A., 3rd, Demarini, D.J., Shah, N.G., Wach, A., Brachat, A., Philippsen, P., and Pringle, J.R. (1998). Additional modules for versatile and economical PCR-based gene deletion and modification in Saccharomyces cerevisiae. Yeast 14, 953-961.

Mayer, A., Wickner, W., and Haas, A. (1996). Sec18p (NSF)-driven release of Sec17p (alpha-SNAP) can precede docking and fusion of yeast vacuoles. Cell 85, 83-94.

Mizuta, K., and Warner, J.R. (1994). Continued functioning of the secretory pathway is essential for ribosome synthesis. Mol. Cell. Biol. 14, 2493-2502.

Nakatsukasa, K., Nishikawa, S., Hosokawa, N., Nagata, K., and Endo, T. (2001). Mnl1p, an alpha-mannosidase-like protein in yeast Saccharomyces cerevisiae, is required for endoplasmic reticulum-associated degradation of glycoproteins. J. Biol. Chem. 276, 8635-8638.

Nishikawa, S., Hirata, A., and Nakano, A. (1994). Inhibition of endoplasmic reticulum (ER)-to-Golgi transport induces relocalization of binding protein $(\mathrm{BiP})$ within the ER to form the BiP bodies. Mol. Biol. Cell 5, 1129-1143.

Novick, P., and Schekman, R. (1979). Secretion and cell-surface growth are blocked in a temperature-sensitive mutant of Saccharomyces cerevisiae. Proc. Natl. Acad. Sci. USA 76, 1858-1862.

Patel, S.K., Indig, F.E., Olivieri, N., Levine, N.D., and Latterich, M. (1998). Organelle membrane fusion: a novel function for the syntaxin homolog Ufe1p in ER membrane fusion. Cell 92, 611-620.

Plemper, R.K., Bohmler, S., Bordallo, J., Sommer, T., and Wolf, D.H. (1997). Mutant analysis links the translocon and BiP to retrograde protein transport for ER degradation. Nature 388, 891-895.

Plemper, R.K., Bordallo, J., Deak, P.M., Taxis, C., Hitt, R., and Wolf, D.H. (1999). Genetic interactions of Hrd3p and Der3p/Hrd1p with Sec61p suggest a retro-translocation complex mediating protein transport for ER degradation. J. Cell Sci. 112, 4123-4134.

Plemper, R.K., Egner, R., Kuchler, K., and Wolf, D.H. (1998). Endoplasmic reticulum degradation of a mutated ATP-binding cassette transporter Pdr5 proceeds in a concerted action of Sec61 and the proteasome. J. Biol. Chem. 273, 32848-32856.

Plemper, R.K., and Wolf, D.H. (1999). Retrograde protein translocation: ERADication of secretory proteins in health and disease. Trends Biochem. Sci. 24, 266-270.

Prinz, W.A., Grzyb, L., Veenhuis, M., Kahana, J.A., Silver, P.A., and Rapoport, T.A. (2000). Mutants affecting the structure of the cortical endoplasmic reticulum in Saccharomyces cerevisiae. J. Cell Biol. 150 461-474.

Rabinovich, E., Kerem, A., Fröhlich, K.U., Diamant, N., and BarNun, S. (2002). AAA-ATPase p97/Cdc48p, a cytosolic chaperone required for endoplasmic reticulum-associated protein degradation. Mol. Cell Biol. 22, 626-634.

Rambourg, A., Clermont, Y., and Kepes, F. (1993). Modulation of the Golgi apparatus in Saccharomyces cerevisiae sec7 mutants as seen by three-dimensional electron microscopy. Anat. Rec. 237, 441-452.

Rambourg, A., Clermont, Y., Ovtracht, L., and Kepes, F. (1995). Three-dimensional structure of tubular networks, presumably Golgi in nature, in various yeast strains: a comparative study. Anat. Rec. 243, 283-293.

Rendueles, P.S., and Wolf, D.H. (1988). Proteinase function in yeast: biochemical and genetic approaches to a central mechanism of post-translational control in the eukaryote cell. FEMS Microbiol. Rev. 4, 17-45.

Rothman, J.E., and Wieland, F.T. (1996). Protein sorting by transport vesicles. Science 272, 227-234.

Rupp, S., and Wolf, D.H. (1995). Biogenesis of the yeast vacuole (lysosome). The use of active-site mutants of proteinase yscA to determine the necessity of the enzyme for vacuolar proteinase maturation and proteinase yscB stability. Eur. J. Biochem. 231, 115-125.

Schekman, R., and Orci, L. (1996). Coat proteins and vesicle budding. Science 271, 1526-1533.

Scherer, S., and Davis, R.W. (1979). Replacement of chromosome segments with altered DNA sequences constructed in vitro. Proc. Natl. Acad. Sci. USA 76, 4951-4955.

Schröder, S., Schimmoller, F., Singer-Krüger, B., and Riezman, H. (1995). The Golgi-localization of yeast Emp47p depends on its dilysine motif but is not affected by the ret1-1 mutation in alphaCOP. J. Cell Biol. 131, 895-912.

Schröder-Köhne, S., Letourneur, F., and Riezman, H. (1998). AlphaCOP can discriminate between distinct, functional di-lysine signals in vitro and regulates access into retrograde transport. J. Cell Sci. $111,3459-3470$.

Sikorski, R.S., and Hieter, P. (1989). A system of shuttle vectors and yeast host strains designed for efficient manipulation of DNA in Saccharomyces cerevisiae. Genetics 122, 19-27.

Sommer, T., and Wolf, D.H. (1997). Endoplasmic reticulum degradation: reverse protein flow of no return. FASEB J. 11, 1227-1233.

Springer, S., and Schekman, R. (1998). Nucleation of COPII vesicular coat complex by endoplasmic reticulum to Golgi vesicle SNAREs. Science 281, 698-700.

Stack, J.H., Horazdovsky, B., and Emr, S.D. (1995). Receptor-mediated protein sorting to the vacuole in yeast: roles for a protein kinase, a lipid kinase and GTP-binding proteins. Annu. Rev. Cell Dev. Biol. 11, 1-33.

Stevens, T., Esmon, B., and Schekman, R. (1982). Early stages in the yeast secretory pathway are required for transport of carboxypeptidase $\mathrm{Y}$ to the vacuole. Cell 30,439-448.

Tokuyasu, K.T. (1989). Use of poly(vinylpyrrolidone) and poly(vinyl alcohol) for cryoultramicrotomy. Histochem. J. 21, 163-171.

Travers, K.J., Patil, C.K., Wodicka, L., Lockhart, D.J., Weissman, J.S., and Walter, P. (2000). Functional and genomic analyses reveal an essential coordination between the unfolded protein response and ER-associated degradation. Cell 101, 249-258.

Tsui, M.M., and Banfield, D.K. (2000). Yeast Golgi SNARE interactions are promiscuous. J. Cell Sci. 113, 145-152. 
Van Den Hazel, H.B., Kielland-Brandt, M.C., and Winther, J.R. (1996). Review: biosynthesis and function of yeast vacuolar proteases. Yeast 12, 1-16.

Vashist, S., Kim, W., Belden, W.J., Spear, E.D., Barlowe, C., and Ng, D.T. (2001). Distinct retrieval and retention mechanisms are required for the quality control of endoplasmic reticulum protein folding. J. Cell Biol. 155, 355-368.

Wooding, S., and Pelham, H.R. (1998). The dynamics of golgi protein traffic visualized in living yeast cells. Mol. Biol. Cell 9, 2667-2680.

Yamamoto, K., Fujii, R., Toyofuku, Y., Saito, T., Koseki, H., Hsu, V.W., and Aoe, T. (2001). The KDEL receptor mediates a retrieval mechanism that contributes to quality control at the endoplasmic reticulum. EMBO J. 20, 3082-3091.
Ye, Y., Meyer, H.H., and Rapoport, T.A. (2001). The AAA ATPase Cdc48/p97 and its partners transport proteins from the ER into the cytosol. Nature 414, 652-656.

Zapun, A., Jakob, C.A., Thomas, D.Y., and Bergeron, J.J. (1999). Protein folding in a specialized compartment: the endoplasmic reticulum. Struct. Fold Des. 7, R173-R82.

Zhang, Y., Nijbroek, G., Sullivan, M. L., McCracken, A. A., Watkins, S. C., Michaelis, S., and Brodsky, J. L. (2001). Hsp70 molecular chaperone facilitates endoplasmic reticulum-associated protein degradation of cystic fibrosis transmembrane conductance regulator in yeast. Mol. Biol. Cell 12, 1303-1314.

Zimmer, T., Vogel, F., Ohta, A., Takagi, M., and Schunck, W.H. (1997). Protein quality - a determinant of the intracellular fate of membranebound cytochromes P450 in yeast. DNA Cell Biol. 16, 501-514. 